\title{
Hagiografias en la era de la Web 2.0
}

\section{Hagiographies in the Web Era 2.0}

\author{
Yves Bernardo Roger Solis Nicot \\ Prepa Ibero Ciudad de México \\ México \\ Correo:yves.solis@prepaibero.mx
}

DOI 10.48102/hyg.vi54.282

\section{ABSTRACT}

This article aims to present new forms of popular and institutional religiosity in the Web 2.0 in the age of YouTube and Facebook. This recent phenomena deserves to receive a renewed methodological and theoretical approach. Since the induction and development of Internet in Latin America and México, new cases of promotion of saints and sanctuaries have appeared. In the first part this article will be a series of thoughts about faith and saint promotion in the Web 2.0. Then we will promote a comparative analysis of digital adhesion that some saints receive in the material and digital world, such as the cases of Yves, a medieval Saint, and Teresa de Calcutta, a contemporary Saint.

Keywords: Hagiography, Web 2.0, Digital Social Networks, Digital Narratives, Digital Hagiography.

\section{RESUMEN}

En la era de YouTube y de Facebook han aparecido en la Web 2.0 nuevas formas de religiosidad popular e institucional. Con la llegada y desarrollo del internet en América Latina y en México, están surgiendo diversos casos de promoción digital de santos y santuarios. Este fenómeno reciente merece un trato teórico y metodológico nuevo. En la primera parte de este artículo se hará una reflexión en torno a la fe y la promoción de santos en la era de la Web 2.0; en la segunda parte se propondrá un análisis comparativo de dos devociones digitales de santos: uno medieval, san Yves, y el otro contemporáneo, santa Teresa de Calcuta. 
Palabras clave: hagiografía, Web 2.0, redes sociales digitales, narrativas digitales, hagiografía digital.

Artículo recibido: 14/07/2019

Artículo aceptado: I2/09/2019

E n la era de la Web 2.0, las redes sociales y la tecnología digital
ocupan cada vez más espacios simbólicos. El internet, que nació como un espacio militar y secularizado, tiene una presencia de contenidos religiosos cada vez mayor. La creación en 1989 de la World Wide Web "como una plataforma abierta que permitiría a todas las personas en todas partes compartir información, tener acceso a oportunidades y colaborar más allá de límites geográficos y culturales", ${ }^{1}$ apoyó esta transformación. Tanto las instituciones religiosas como los fieles están usando las páginas de internet para promover su fe y sus creencias. ${ }^{2}$ Ello provoca una serie de retos para una institución tan centralizadora como la Iglesia católica. ${ }^{3}$

Por lo tanto, el estudio de nuevas narrativas en torno a la promoción de figuras de santos es cada vez más importante en esta era digital. Algunos personajes cuyas causas de beatificación o canonización corresponden ya al siglo XXI tienen presencia en YouTube, perfiles en Facebook y son "amigos" de otros santos o grupos católicos, lo que marca una transformación en las narra-

${ }^{1}$ Tim Berners-Lee, "Three Challenges for the Web", Web Foundation, 12 de marzo de 2017. Disponible en: <http://webfoundation.org/2017/03/web-turns-28-letter/\#VersionES>.

${ }^{2}$ En 2012, Pauline Hope Chong et al. coordinaron una interesante obra que permite una amplia reflexión en torno al acercamiento a la religión digital, los medios sociales y los aspectos culturales. Entre las discusiones se analizó la importancia de la Web, de la Web 2.0 y de la Web 3.0. Pauline Hope Cheong, Peter Fischer-Nielsen, Stefan Gelfgren y Charles Ess (eds.), Digital Religion, Social Media, and Culture: Perspectives, Practices, and Futures.

${ }^{3}$ Yves Solis, "De la centralización romana a la descentralización de las redes sociales: la promoción de la figura de Luis María Martínez, Siervo de Dios, en la Web 2.0. YouTube". 
tivas hagiográficas tradicionales y permite así -a la escritura de la vida de los santos- un papel que rebasa la leyenda en su sentido latino de legenda: más allá de ser un texto que debe ser leído, se vuelve la vida proyectada en redes sociales, videos en YouTube y páginas de internet.

A través de iniciativas institucionales y una estrategia de medios orquestada desde Roma, la Iglesia católica intenta usar las ventajas del internet para emprender obras evangelizadoras como la promoción de los santos. Ello representa la continuidad de una tradición que inició a principios del siglo $\mathrm{xx}$ con el intenso uso de la radio, la televisión y el cine. ${ }^{4}$ Sin embargo, internet también permite a los fieles promover o difundir las devociones de manera directa, sin pasar por el visto bueno de la jerarquía, del sacerdote ni de la comunidad. En este sentido, está surgiendo una tensión entre la narrativa oficial promovida desde la Iglesia institucional y las generadas por los fieles; una tensión similar a la que se daba en la Edad Media entre las hagiografías oficiales y las diferentes tradiciones orales. La premisa del artículo es hacer visible esta tensión entre discurso institucional y posturas personales frente a la santidad a través del estudio de tres casos: un santo contemporáneo mexicano cuya devoción es todavía regional, un santo medieval francés cuya devoción originalmente regional rebasa los límites locales y tiene un umbral nacional, y una santa contemporánea armenia cuya representatividad es mundial. Los tres reciben muestras de fe y devoción en internet, donde sus hagiografías digitales se encuentran a un clic de distancia.

Para entender mejor esta tensión, reflexionaremos en torno a la Legenda aurea y las narrativas oficiales promovidas en el siglo xxI. Después realizaremos una comparación entre la hagiografía

${ }^{4} I d e m$. En esta reflexión anterior propongo un breve esbozo de las principales ediciones de la Jornada Mundial de las Comunicaciones Sociales, promovidas desde la Santa Sede para orientar a los comunicadores católicos que participan activamente en espacios cinematográficos, radiofónicos y televisivos. 
y los perfiles de Facebok de san Yves (espańolizado como san Ivo o san Ivón) y la promoción de dos nuevos santos, canonizados en 2016: Teresa de Calcuta y José Sánchez del Río.

\section{De la LEGENDA AUREA A LA NARRATIVA Digital}

\section{I Hagiografia medieval}

Es muy difícil acercarse al análisis de la hagiografía sin hacerlo al periodo de uno de sus principales momentos de producción: la Edad Media. Si antes era necesario recurrir a bibliotecas y fondos de archivos, el desarrollo de internet ha permitido tener acceso a esos documentos en fuentes y bases de datos. La hagiografía tradicional se puede encontrar ahora a un clic de distancia. Iniciativas como Gallicas o "Survey of Dedications to Saints in Medieval Scotland" son herramientas que hacen posible al lego acercarse a la construcción y promoción cultural de los santos.

La base de datos puede ser consultada para, por ejemplo, encontrar información sobre santos particulares, grupos de santos de tipos similares (como vírgenes mártires), por tipo particular de dedicación (por ejemplo, altares), por quién les rinde homenaje (como burgueses u obispos), por el tipo de devoción asociada a algún lugar en particular, a tal o cual iglesia, a una orden religiosa. Esas búsquedas pueden darse en lo individual o combinándolas. De manera alterna, si un usuario desea analizar la información contenida en la base de datos de una manera más compleja o de acuerdo con sus propios criterios, se puede descargar gratis toda la base de datos en su forma de tabla de Microsoft Access a través del sitio web. ${ }^{7}$

\footnotetext{
${ }^{5}$ Gallica es la biblioteca numérica de la biblioteca nacional de Francia.

${ }^{6}$ Steve Boardman, John Davies y Eila Williamson, "Survey of Dedications to Saints in Medieval Scotland".

${ }^{7}$ Steve Boardman, "The Survey of Dedications to Saints in Medieval Scotland", p. 189.
} 
Si bien este tipo de iniciativas no representa una muestra o demostración de fe, nos permite acceder a las devociones ${ }^{8}$ de la época medieval para poder entonces encontrar similitudes y diferencias con las prácticas presentes en la World Wide Web. Quienes pusieron en línea este acervo documental sostienen: "La base de datos puede resultar particularmente útil para quienes se interesen en el estudio del culto de los santos al permitirles examinar tanto cronológica como espacialmente la difusión de devociones particulares". ${ }^{9}$

En el caso de Gallica existe una doble riqueza documental. La primera es el acceso a las fuentes primarias, a los manuscritos y documentos que componen la Legenda aurea. ${ }^{10}$ La segunda, el acceso a diversos textos de quienes, en diferentes momentos de la historia, han estudiado de modo científico las narrativas en torno a la santidad y la hagiografía. De esta manera, por ejemplo, el

\section{${ }^{8}$ Ibidem, pp. 189-190.}

${ }^{9}$ Ibidem, p. 190. He aquí una exposición más amplia del proyecto: "In historiographical terms the Survey has been designed to address some problematic features that seem to have restricted the modern study of saints' cults and piety in medieval Scotland. The first of these is the dearth of surviving examples of Scottish provenance of organized collections of miracle stories focused on individual shrines and/or continuously maintained records of the gifts bestowed on the clerical custodians of important relics. Fine textured analysis of the operation of saints' cults in medieval Scotland is rather difficult given the scarcity of this particular source type. Books of Hours and psalters that might give us an insight into an individual's or a family's pious concerns and interests are similarly rare. In short, it has often been difficult to say anything very coherent about saints' cults and piety in medieval Scotland because of the scattered and fragmentary nature of the available sources. The Saints project is intended to ameliorate the problem of the gaps in Scottish source material by collecting and collating the incidental references to saints from across the range of documentary sources that have survived".

${ }^{10}$ La Legenda aurea es una obra escrita en latín por el arzobispo de Génova, el dominico Jacobus de Voragine. Presenta la vida de numerosos santos, santas y mártires cristianos. La transcripción en latín del texto original se puede encontrar en la biblioteca latina: <http://www.thelatinlibrary.com/vorag.html>, y algunas digitalizaciones del documento original en la biblioteca digital de Berkeley: <http://dpg.lib.berkeley.edu/webdb/dsheh/heh_brf?Description=\&CallNumber $=\mathrm{HM}+3027>$. 
Diccionario de hagiografia de 1925 -una mezcla de estudio literario y trabajo positivista- presenta un interesante caso de uso de la hagiografía como ciencia auxiliar de la historia. Y ésta no es la única obra que le da ese papel a la hagiografía. ${ }^{11}$

Quien más ha trabajado en torno a la historia de la santidad desde los mártires hasta la Reforma es Robert Bartlett. ${ }^{12}$ De acuerdo con él, "Por más de mil años, la hagiografía, es decir, lo escrito sobre los santos y sus poderes milagrosos, fue una de las principales ramas de la literatura europea. Aun después de la irrupción de la Reforma protestante, continuó siendo una parte importante del mundo cultural de la Europa católica y ortodoxa". ${ }^{13}$ La hagiografía sobrevivió a la modernidad, y el paso de narrativas medievales a narrativas modernas puede ser estudiado a través de vidas de santos producidas en diferentes épocas y momentos, tal como es el caso de la novela Der Erwählte (El elegido), de Thomas Mann.

\section{I.2 Hagiografia y modernidad}

En 2010, Jutta Eming propuso un análisis de dicha novela del escritor alemán Thomas Mann que, a pesar de sus contradicciones, identifica un vínculo entre la hagiografía medieval y la modernidad. ${ }^{14}$

\footnotetext{
${ }^{11}$ Se puede ver en este sentido una serie de reflexiones en torno a la hagiografía como ciencia auxiliar de la historia al mismo nivel que la teología, la liturgia, la filosofía o el derecho canónico. Cabe resaltar la obra de Robert Bartlett, Why Can the Dead Do Such Great Things?: Saints and Worshippers from the Martyrs to the Reformation. También resulta interesante una reflexión de principios del siglo xx: Catholic University of America Press, "Part I: The Auxiliary Sciences". ${ }^{12}$ En los últimos años se ha dado en los Estados Unidos una renovación de los estudios en torno a la construcción de la santidad y la difusión de las figuras de santos. Aparte de la obra monumental de Bartlett, se pueden mencionar dos estudios más: Laura A. Smoller, The Saint and the Chopped-Up Baby: The Cult of Vincent Ferrer in Medieval and Early Modern Europe; y Mathew Kuefler, The Making and Unmaking of a Saint: Hagiography and Memory in the Cult of Gerald of Aurillac.

${ }^{13}$ Bartlett, Why Can the Dead...?, op. cit., p. 504.

${ }^{14}$ Jutta Eming, "Chopped up, Grilled and Shrunken to the Size of a Hedgehog: The Bodies of Saints in Medieval Hagiography and in Thomas Mann's Der Erwählte".
} 
Eming plantea que las vidas de santos eran la literatura más popular de la premodernidad y que siguen resonando en el contexto cristiano contemporáneo. Entrar al mundo de lo escrito significa, por lo tanto, aprender a leer literatura religiosa. De acuerdo con la estudiosa alemana, las historias compiladas en la Legenda aurea de Jacobo de la Vorágine establecen una fuerte tradición de transmisión, preservación y representación de lo sagrado para los cristianos europeos y permiten establecer el contexto de muchos textos medievales. ${ }^{15}$ Para ella, la hagiografía, al estar enraizada en la religión cultural, asume un estatuto a medio camino entre el objeto sagrado y la literatura, entendida en el sentido moderno de la palabra. Así, la narrativa es "buena" no por contar una historia de santidad, sino porque permite a los miembros de la comunidad religiosa acordarse de los fundamentos de su fe.

En la Edad Media, tanto las narrativas escritas como las artes visuales retrataron escenas de violencia extrema en las cuales los cuerpos de los santos eran lastimados, mutilados, quemados, escaldados y torturados hasta la muerte de las maneras más brutales que se puedan imaginar. Siguiendo a Eming, el sentido de esas narrativas ya no es transparente para el lector moderno. Los investigadores contemporáneos se han preguntado cuál era la mentalidad de los públicos para los que fueron generadas dichas narrativas. ¿Por qué existía esta fascinación por la brutalidad? El sentido religioso parece desdibujarse frente a tanta violencia. Sin embargo, detrás de la violencia viene la resurrección, la salvación que sólo puede ser entendida desde el contexto de la cultura re-

${ }^{15}$ Además del original en latín mencionada en la nota 10 , existen versiones disponibles en francés, catalán e italiano, en la página los Archivos de Literatura de la Edad Media, Arlima: <https://www.arlima.net/il/iacopo_da_varazze. html\#>. También existe una traducción al inglés, publicada por la universidad norteamericana de Fordham: <https://sourcebooks.fordham.edu/basis/goldenlegend/>. No he encontrado versión digital de la traducción de fray José María Macías. Tal vez se deba a que el libro fue publicado nuevamente por la editorial Alianza en 2014: <https://www.alianzaeditorial.es/libro.php?id=3593174\&id_ col $=100508>$. 
ligiosa y que ha perdurado y sobrevivido a la modernidad. ${ }^{16}$ Por ello, Eming sitúa a la hagiografía como una creación que se encuentra entre la práctica religiosa y la literatura. "De la Edad Media a la modernidad, lo sagrado transita a la literatura a través de un número importante de alteraciones, sobre todo en cuanto al estatus del narrador". ${ }^{17}$ Es decir, que la hagiografía, producto de la cultura medieval, ha sobrevivido en la moderna Europa y se ha trasformado y adaptado a los nuevos códigos culturales de los siglos XV y XVI y sigue existiendo en el XXI.

Anna Taylor, en su estudio sobre la hagiografía, profundiza un poco más la propuesta de Eming:

Los estudiosos modernos usan el concepto de hagiografía para designar tanto al cuerpo de literatura como al estudio de dichas fuentes. (Algunos estudiosos llaman a esta última hagiología para evitar confusión en torno al concepto). El cuerpo de la hagiografía (en este último sentido) se ha definido, o por su función (promoción del culto de los santos) o por su contenido (santo). Bajo cualquiera de esas definiciones, la hagiografía cubre un vasto número de textos, seguramente la parte más importante de la literatura medieval. Incluye narrativas tales como las vidas de los santos, pasiones, colección de milagros, visiones, invenciones (basadas en el descubrimiento de las reliquias) y traducciones (basadas en el traslado de las reliquias). Algunos estudios incluyen también trabajos litúrgicos como la martirología, las letanías o los calendarios, mucho menos estudiados. ${ }^{18}$

Para Taylor, desde los orígenes modernos de la disciplina los historiadores delinearon una forma de estudiar la hagiografía. Los primeros autores positivistas decidieron ignorar los escritos sobre

\footnotetext{
${ }^{16}$ Eming, "Chopped up...”, op. cit., pp. 146-147.

${ }^{17}$ Ibidem, p. 147. "From the Middle Ages to modernity the sacred makes a transition to the literary through a number of major alterations, especially with respect to the status of the narrator".

${ }^{18}$ Anna Taylor, "Hagiography and Early Medieval History", p. 3.
} 
santos o pretendieron "liberar" a los hechos del aparato fantástico que los rodeaba. ${ }^{19}$ En las últimas décadas del siglo $\mathrm{xx}$, los medievalistas usaron numerosas metodologías para analizar esos documentos y acercarse a la amplia gama de ideas y prácticas que los acompañaba. Sin embargo, tales estudiosos han usado la lectura de los textos como evidencia del contexto de sus autores más que como una representación fidedigna del pasado. De acuerdo con Taylor, sin embargo, el trabajo antropológico de Brown ${ }^{20}$ sobre el rol del hombre santo y los estudios de Bynum ${ }^{21}$ sobre género, piedad y cuerpo han sido de gran influencia. El interés de los estudios medievales en el tema de la alteridad desde los años ochenta ha promovido un acercamiento a lo maravilloso y, por lo tanto, a la santidad. Para Taylor es importante dejar en claro que "la hagiografía es un constructo moderno que con frecuencia es tratado como una realidad medieval. Tanto la hagiografía como la idea del género en sí son demasiado restrictivas para entender la gran diversidad de los escritos sobre santos. La creatividad de varios trabajos y la fluidez de las tradiciones literarias han sido oscurecidas por ideas anacrónicas sobre la hagiografía y el género". ${ }^{22}$

La hagiografía, lejos de decaer con la modernidad, generó nuevas formas de presentar la santidad. Tal es el caso de la obra de Claude Martin, estudiada por Mary Dunn. ${ }^{23}$ Para la profesora Dunn, la vida de la venerable madre María de la Encarnación, escrita por éste, ${ }^{24}$ hijo de la monja, representa solamente un eco a la voz propia de María de la Encarnación. El caso es muy relevante

\footnotetext{
${ }^{19}$ Idem.

${ }^{20}$ Peter Brown, "The Rise and Function of the Holy Man in Late Antiquity".

${ }^{21}$ Caroline Walker Bynum, Jesus as Mother: Studies in the Spirituality of the High Middle Ages; e Id., Holy Feast and Holy Fast: The Religious Significance of Food to Medieval Women.

${ }^{22}$ Taylor, "Hagiography and Early...", op. cit., p. 1.

${ }^{23}$ Mary Dunn, “But an Echo'?: Claude Martin, Marie de l'Incarnation, and Female Religious Identity in Seventeenth-Century New France”.

${ }^{24}$ Claude Martin (1619-1696), monje benedictino de la congregación de SaintMaur. Publicó en 1677 La vie de la mère Marie.
} 
porque Martin ${ }^{25}$ siguió, como su madre, una vocación religiosa y fue quien promovió la primera hagiografía de la misma en el contexto de la Contrarreforma. Dunn muestra en su estudio que

una lectura más detallada sugiere que Claude domina tanto la narrativa de la vida de su madre, que la Vie emerge como un ejemplo de hagiografía y apología que hace de María un modelo de santo de la Contrarreforma, un paradigma de la devoción católica postridentina y de hija obediente para con la jerarquía eclesiástica patriarcal, representando así un esfuerzo para dibujar los límites de la identidad religiosa en la nueva Francia premoderna. ${ }^{26}$

Con la beatificación en 1980 por Juan Pablo II, el caso de María de la Encarnación es interesante también por la utilización política del proceso de canonización. Toda proporción guardada, la lucha de Claude Martin para lograr la beatificación de su madre tiene puntos en común con el proceso de José Sánchez del Río. En efecto, la figura de los mártires no siempre responde solamente al sacrificio y la imitación de Cristo en la defensa de la fe hasta la muerte: un mártir puede ser utilizado también para otros fines distintos a la "mayor gloria de Dios". Es el caso de José Sánchez del Río, mártir adolescente beatificado en 2005 y canonizado en 2016. Su figura la usó en 2003 el padre Marcial Maciel en su libro Mi vida es Cristo. ${ }^{27}$ El testimonio de su martirio se propone en el texto como un hito fundamental en el despertar vocacional del padre Maciel. La presencia de este santo en el origen de su camino cristiano, así como la cercanía biográfica a otras personas consideradas santas, como su tío Rafael Guízar y Valencia (canonizado

\footnotetext{
${ }^{25}$ Marie de l'Incarnation, cuyo nombre de mujer casada fue Marie Guyart, es un ejemplo de santas quienes, como Santa Rita de Casia o la venerable Concepción Cabrera de Armida, tuvieron que casarse y retrasaron así su vida de vocación.

${ }^{26}$ Dunn, “But an Echo'?...”, op. cit., p. 477.

${ }^{27}$ Jesús Colina, Mi vida es Cristo: entrevista a Marcial Maciel, LC. Fundación Logos, 2003.
} 
el 15 de octubre de 2006) y su propia madre, las empleó como señales de que Cristo había acompañado el andar del fundador de los legionarios hacia los altares; camino truncado en el ańo 2005, cuando se le invitó a retirarse de la legión, tras las múltiples acusaciones formales de cometer abusos sexuales a varios miembros de la congregación y estudiantes de los establecimientos de los legionarios, y en 2006 se le pidió también dejar la vida pública. En 2008, tras su muerte, otros escándalos relativos a su vida de pareja y su relación con una hija suya, aumentaron su desprestigio. ${ }^{28} \mathrm{Al}$ año siguiente, las fotografías del fallecido religioso y fundador de los Legionarios de Cristo fue retirada de las instalaciones de la organización, que reconoció las graves faltas de su fundador. ${ }^{29}$

El 3 de abril de 2014 el papa Francisco elevó a los altares a María Guyart, santa María de la Encarnación, mística ursulina, misionera católica y fundadora de las Ursulinas de la Nueva Francia, mediante la canonización equipolente, un proceso que permite declarar santa a una persona por decreto y sin ceremonia ni juicio canónico. ${ }^{30}$ Esta metodología, prevista en el derecho canónico:

Se aplica cuando un hombre o una mujer es beato, beata, desde hace mucho tiempo y tiene la veneración del pueblo de Dios, que de hecho lo venera como santo, y no se hace el proceso. Hay algunos casos así desde hace siglos. El proceso de Ángela de Foligno fue así; ella fue la primera. Después decidí hacer lo mismo con personas que han sido grandes evangelizadores y evangelizadoras. En primer lugar, Pedro Fabro, que fue un gran

28 “Marcial Maciel, la amante y su hija”, El Pais, 6 de marzo de 2011: <https:// elpais.com/diario/2011/03/06/domingo/1299387161_850215.html>.

29 "Retirarán imagen del Padre Maciel”. El Universal, 4 de septiembre de 2009: $<$ https://archivo.eluniversal.com.mx/notas/624379.html>.

${ }^{30}$ Papa Francisco, "Encuentro del santo padre con los periodistas durante el viaje a Manila”, 15 de junio de 2015. Disponible en: <https://w2.vatican.va/content/ francesco/es/speeches/2015/january/documents/papa-francesco_20150115_ srilanka-filippine-incontro-giornalisti.html>. 
evangelizador de Europa: murió - podríamos decir-en el camino, cuando, con cuarenta años, viajaba para evangelizar. Y después vinieron los demás: los evangelizadores de Canadá, Francisco de Laval y María de la Encarnación, que, por el gran apostolado que hicieron, fueron prácticamente los fundadores de la Iglesia en Canadá, siendo él Obispo y ella religiosa. El siguiente fue José de Anchieta, de Brasil, fundador de São Paulo, que hacía tiempo que era beato, y ahora es santo. José Vaz, aquí, como evangelizador de Sri Lanka. Y en septiembre próximo, Dios mediante, haré la canonización de Junípero Serra, en los Estados Unidos, porque fue el evangelizador del oeste de los Estados Unidos. Son figuras de grandes evangelizadores, que están en sintonía con la espiritualidad y la teología de la Evangelii gaudium. Y por eso he elegido esas figuras. ${ }^{31}$

El procedimiento, a pesar de ser poco común, está previsto. Juan Pablo II canonizó a tres santos por esta vía y Benedicto XVI, a uno. ${ }^{32}$ Ahora bien, es importante explicar las condiciones bajo las cuales puede suceder:

Sólo puede darse cuando son reunidas tres condiciones precisas: una existencia antigua del culto, la atestación constante y común de historiadores fidedignos de las virtudes o el martirio y una fama ininterrumpida de milagros. Tal es la doctrina plurisecular de la Iglesia, teorizada por el papa Benedicto XI. Como se puede ver, la fama de milagros no se encuentra para nada ausente de esta canonización, que recompone el quinteto de los santos testigos de la evangelización americana, de una manera tal que se pueda apreciar que cada evangelización, sea vieja o nueva, tiene como preámbulo y fuente indispensable la santidad de una vida virtuosa. ${ }^{33}$

${ }^{31} \mathrm{Idem}$.

${ }^{32}$ John L. Allen Jr. "It’s Official: Jesuit Fr. Peter Faber Is a Saint", National Catholic Reporter, 17 de diciembre de 2013. Disponible en : <https://www.ncronline. org/blogs/its-official-jesuit-faber-saint $>$.

${ }^{33}$ Nicola Gori, "Le cardinal Amato parle des trois canonisations équipollentes", 
Esos tres ejemplos demuestran cómo, frente a estrategias de grupos de presión dentro de la Iglesia católica, la Santa Sede responde con el decreto de canonización que abre al culto público la dulía para el nuevo santo. El grupo de presión logra así que la figura del santo quede inscrita en el martirologio romano y pueda ser objeto de devoción, aun cuando su figura no recibe una devoción previa importante. ${ }^{34}$ Se puede ver así un uso político de la devoción de los santos que responde a una figura que los grupos particulares desean propagar, más que un ejemplo de devoción popular.

\section{3 "Los santos del nuevo milenio"35}

Francisco sigue la tradición de canonizar en masa, inaugurada por Juan Pablo II. ${ }^{36}$ No sólo ha rebasado el número de santos enaltecidos por él, sino que también realizó la exaltación simultánea más

Osservatore Romano, 3 de abril de 2014. Disponible en: <http://www.news.va/ $\mathrm{fr} /$ news/le-cardinal-amato-parle-des-trois-canonisations-eq $>$.

${ }^{34}$ Sobre este punto se puede consultar en particular la tesis doctoral de Amilcar Carpio Pérez, "Los procesos de santidad: la construcción de una devoción".

${ }^{35}$ Para este apartado se decidió retomar el título de un pseudopoema "Los santos del milenio", adjudicado primero a Juan Pablo II y después a Francisco en ocasión de las jornadas mundiales de la juventud. El primero habló de los santos del nuevo milenio en su texto de invitación a las jornadas mundiales que se celebrarían en Roma en el 2000: "Mensaje para la xv Jornada Mundial de la Juventud”, 29 de junio de 1999, n. 3: L'Osservatore Romano, edición en lengua española, 9 de julio de 1999, p. 2. Disponible en: <http://w2.vatican.va/content/john-paul-ii/es/messages/youth/documents/hf_jp-ii_mes_29061999_xvworld-youth-day.html>. Para leer en torno al pseudopoema se puede consultar a Redacción Central, "Bulos en la red: El poema que el Papa Francisco no escribió y las frases que no tuiteó”, Aciprensa, 26 de septiembre de 2013. Disponible en: <https://www.aciprensa.com/noticias/bulos-en-la-red-el-poema-que-el-papa-francisco-no-escribio-y-las-frases-que-no-tuiteo-43677/>. Es interesante que varios católicos hayan difundido en redes y hayan reflexionado sobre un mensaje que ni Juan Pablo II ni Francisco escribieron. Mario González, "Santos del nuevo milenio" El salvador.com, 3 de agosto de 2013. Disponible en: <http:// www.elsalvador.com/articulo/editoriales/santos-del-nuevo-milenio-36984>. ${ }^{36}$ Canonizzazioni del Santo Padre Giovanni Paolo II, Ufficio delle Celebrazioni Liturgiche, del Sommo Pontefice. Disponible en: <http://www.vatican.va/ news_services/liturgy/saints/ELENCO_SANTI_GPII.htm >. 
grande de la Iglesia católica: en 2013 declaró santos en la ciudad de Otranto a 813 mártires que resistieron y murieron frente al invasor turco. ${ }^{37}$ En la gráfica siguiente se muestra el aumento en la proclamación de santos desde Paulo VI hasta Francisco.

Durante su corto pontificado, Francisco ha elevado a los altares a fundadores o cofundadores de órdenes o congregaciones, misioneros, sacerdotes y una familia laica: los padres de Teresa de Lisieux. Una de las decisiones más mediáticas fue la canonización de Juan Pablo II y Juan XXIII. ${ }^{38}$ Sin embargo, el actual papa ha canonizado sobre todo a mártires (817), desde Antonio Primaldo y sus compañeros hasta el joven José Sánchez del Río o Salomón Leclerq en 2016. A juzgar por esta cifra, la cuestión del martirio ${ }^{39}$ parece ser uno de los temas predilectos del papa Francisco. Para Philpott:

la Iglesia en sí ha empezado a ver cada vez más que el reconocimiento del martirio puede promover la justicia al ampliar su visión de quién puede considerarse mártir. Antes, un mártir era aquel que era asesinado estrictamente en odium fidei, por odio a la fe. Sin embargo, cada vez más la Iglesia ha empezado a reconocer como mártires a quienes no fueron asesinados por su fe, sino por los actos de justicia motivados por su fe. ${ }^{40}$

\footnotetext{
37 "New Catholic Saints Include a Colombian Nun", The New York Times, 12 de mayo de 2013. Disponible en: <http://www.nytimes.com/2013/05/13/world/ europe/pope-francis-names-several-new-saints.html>.

${ }^{38}$ Es interesante ver que en la página del Vaticano la lista de santos más actualizada es la de las canonizaciones de Juan Pablo II: <http://www.vatican.va/ news_services/liturgy/saints/index_canoniz-beat_en.html>. Para contar con la información más actualizada sobre quiénes han sido canonizado por el papa Francisco, véase Congregazione delle cause dei santi, "Santi proclamati da Papa Francesco". Disponible en: <http://www.causesanti.va/content/causadeisanti/it/santi/santi-proclamati-da-francesco.html>.

${ }^{39}$ Sobre el tema del martirio se puede consultar a Marisol López Menéndez, Miguel Pro: Martyrdom, Politics, and Society in Twentieth-Century Mexico.

${ }^{40}$ Daniel Philpott, "Modern Martyrs", p. 15.
} 


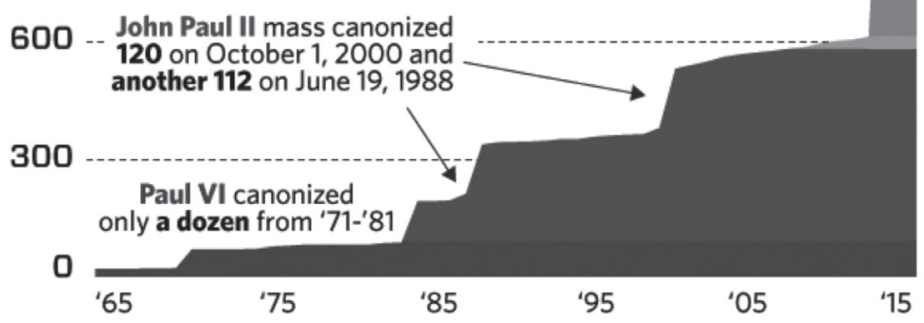

Gráfica 1

Brian Patrick Byrne, "Canon Fodder: Pope Francis Has Declared A Record Number of Saints", Vocativ, 23 de septiembre de 2015. Disponible en: <http://www.vocativ.com/233963/canon-fodder-popefrancis-has-declared-a-record-number-of-saints/index.html>.

Con las canonizaciones masivas, el papa Francisco también está haciendo un cambio radical en el "costo de la santidad". Juan Pablo II, que declaró santas a 482 personas y beatificó a 1138 más, permitió que el dinero fuera un factor fundamental en los procesos vaticanos. ${ }^{41}$ Por ello, el 4 de marzo de 2016 Francisco estableció una serie de reglas para limitar los costos de los procesos de canonización, ${ }^{42}$ las cuales entraron en vigor para los santos "en camino" y no para los que estudiaremos en este artículo. ${ }^{43}$ Las normas del nuevo reglamento establecen que se llevará a cabo un periodo de experimentación, del 7 de marzo de 2016 al 7 de

\footnotetext{
${ }^{41}$ Gerard O’Connell, “Money and Saint-Making”, p. 28.

${ }^{42}$ Véase: $<$ http://press.vatican.va/content/salastampa/es/bollettino/pubblico/20 I 6 /03/ Io/rescripto.html>.

${ }^{43}$ Véase: <http://press.vatican.va/content/salastampa/es/bollettino/pubblico/20 I 6 /03/Io/normas.html>.
} 
marzo de 2019. ${ }^{44}$ El sentido de esta reforma, que viene a reemplazar lo establecido por Juan Pablo II en 1983, se expresa en el preámbulo del documento:

Las causas de beatificación y de canonización requieren, debido a su complejidad, de mucho trabajo y gastos para lograr la promoción del conocimiento de la figura del siervo de Dios o del bienaventurado, tanto para la investigación diocesana o parroquial, como para la fase romana o para las celebraciones de la beatificación o canonización.

En lo que concierne a la fase romana, la sede apostólica, al ver la naturaleza particular del bien público de las causas, apoya en los gastos ocasionados a los promotores al participar, a través de contribuciones financieras, y procura que los honorarios y gastos sean limitados, sin impedir el seguimiento del proceso. ${ }^{45}$

Este fondo de solidaridad es parte de las novedades de las normas y podrá ser usado por el promotor de la causa en caso necesario. ${ }^{46}$ La Divinus Perfectionis Magister, promovida por Juan

${ }^{44}$ Parolin, Pietro, "Rescriptum ex Audientia Sanctissimi”, 7 de marzo de 2016. Disponible en: <http://www.vatican.va/roman_curia/congregations/csaints/documents/rc_con_csaints_doc_20160307_norme-beni-cause_fr.html>.

${ }^{45}$ Angelo Amato y Marcello Bertolucci, Normes sur l'administration des biens des causes de béatification et canonisation, Vatican, 4 de marzo de 2016. La congregación para la causa de los santos propone dos documentos oficiales más, en francés y en inglés; opté por trabajar con el texto en francés: "Les causes de béatification et de canonisation, qui en raison de leur complexité, requièrent beaucoup de travail, entraînent des dépenses pour la divulgation de la connaissance de la figure du serviteur de Dieu ou du bienheureux, pour l'enquête diocésaine ou éparchiale, pour la phase romaine et, enfin, pour les célébrations de béatification ou de canonisation. / En ce qui concerne la phase romaine, le Siège apostolique, étant donnée la nature particulière du bien public des causes, en soutient les coûts, auxquels les promoteurs participent par le biais d'une contribution, et veille à ce que les honoraires et les dépenses soient contenues, le tout sans en empêcher la poursuite". Disponible en : <http://www.vatican.va/roman_curia/ congregations/csaints/documents/rc_con_csaints_doc_20160307_norme-beni-cause_fr.html>.

${ }^{46}$ Ibidem, Art. 22. 
Pablo II el 25 de enero de 1983, que habla sobre la legislación relativa a las causas de los santos, no tomaba en cuenta este aspecto.

Con el nuevo impulso a la promoción de los santos, aunado al auge de los medios digitales, se está verificando también una renovación de la hagiografía tradicional.

2. "Viejo" SANTo, nuevos SANTOS

\section{I San Yves Heloruy de Kermartin}

Para ayudar al análisis de estas nuevas narrativas, es importante entender las motivaciones y la lógica de los casos de hagiografías medievales que han sobrevivido la Modernidad y siguen presentes en la era digital. Un ejemplo de ellas es la devoción a san Yves, ${ }^{47}$ también conocido como san Ivo o san Ivón y considerado patrono de los abogados. ${ }^{48}$

La importancia de san Yves, concentrada de manera especial en Francia, Bélgica y Luxemburgo, rebasa los límites de Europa, ya que también es venerado en América. ${ }^{49}$ En 2003 su figura fue objeto de un coloquio y una obra colectiva, en cuya introducción Jean Christophe Cassard y George Prevost se preguntaban:

¿Es necesario en ocasión del séptimo centenario de su muerte, regresar a la existencia de Yves Hélori? Las universidades de Brest y de Rennes prefieren interrogarse por el destino póstumo del santo: ¿qué ha pasado con su figura para las generaciones que se han sucedido desde ese 19 de mayo de 1303, cuando entregó su alma en su señorío de Kermartin? Desde el principio surgen a la memoria imágenes traídas de la hagiografía oficial o de la tradicional oral, producto de la emoción suscitada por tal o cual obra, nutridas por la observación del perdón de Tréguier. ${ }^{50}$ San Yves

\footnotetext{
${ }^{47}$ Charles Germain Marie Bourel de La Roncière, Saint Yves (1253-1303).

${ }^{48}$ Ibidem, p. 25.

${ }^{49}$ Ibidem, p. 47.

${ }^{50} \mathrm{El}$ "perdón" es la fiesta popular que conmemora al santo. Recibe el nombre de
} 
es el patrono de los hombres de ley, pero también un modelo sacerdotal. Entre el rico y el pobre, el oficial encarna un ideal de justicia, de caridad, pero pudo ser también un taumaturgo. Es asimismo un personaje emblemático para los bretones, quienes se reconocen en él: en Tréguier, pero también en París o en Roma. A lo largo de los siglos, san Yves ha sido objeto de culto en diversos contextos: entre hombres de Iglesia, estudiantes, gente de justicia, peregrinos ordinarios o portadores de la bandera de la independencia de Bretańa, desde los duques de la dinastía de Montfort hasta el historiador Arturo de La Borderie a finales del siglo xix. Culto, imágenes, memoria: todas las formas de recordar a san Yves merecerían ser interrogadas, medidas y, si es posible, fechadas. ${ }^{51}$

La vida de san Yves ha sido analizada por "estudiosos, sacerdotes, religiosos y hasta jurisconsultos" ${ }^{52}$ En cuanto a su culto, éste atravesó tiempos difíciles durante la guerra de los Cien Años, las guerras de religión y el terror: "Sin embargo, debido a un justo restablecimiento de las cosas, la expansión del culto retomaba su vuelo de manera más fuerte, debido a que la imagen del juez íntegro, en medio de las pasiones desenfrenadas, aparecía radiante". ${ }^{53}$

La figura de san Yves no se queda en las imágenes idílicas. El Instituto Nacional Audiovisual de Francia guarda en sus archivos en línea varios programas sobre el perdón de Tréguier. Los documentos visuales muestran la fe y la devoción, la importancia del culto a las reliquias y la perspectiva histórica del evento. En una grabación del perdón de 1964 (Figura 3) se puede ver la impor-

perdón por el carácter penitencial de la procesión. Sobre el tema de los perdones de Bretaña francesa se puede consultar la obra de Bernard Rio, Sur les chemins des pardons et pèlerinages en Bretagne; acerca del perdón de san Yves se puede consultar el capítulo 2 de esa obra, "La vérité selon saint Yves", pp. 37-51, y a Jacques Provost, "Le rituel du pardon de Saint-Yves (XvI $-\mathrm{XX}^{\mathrm{e}}$ siècles)".

${ }^{51}$ Jean Christophe Cassard y George Prevost (dirs.), "Presentation”, en Saint Yves et les Bretons: Culte, images, mémoire (1303-2003).

${ }^{52}$ La Roncière, Saint Yves (1253-1303), op. cit., p. 2.

${ }^{53}$ Ibidem, p. 3. 


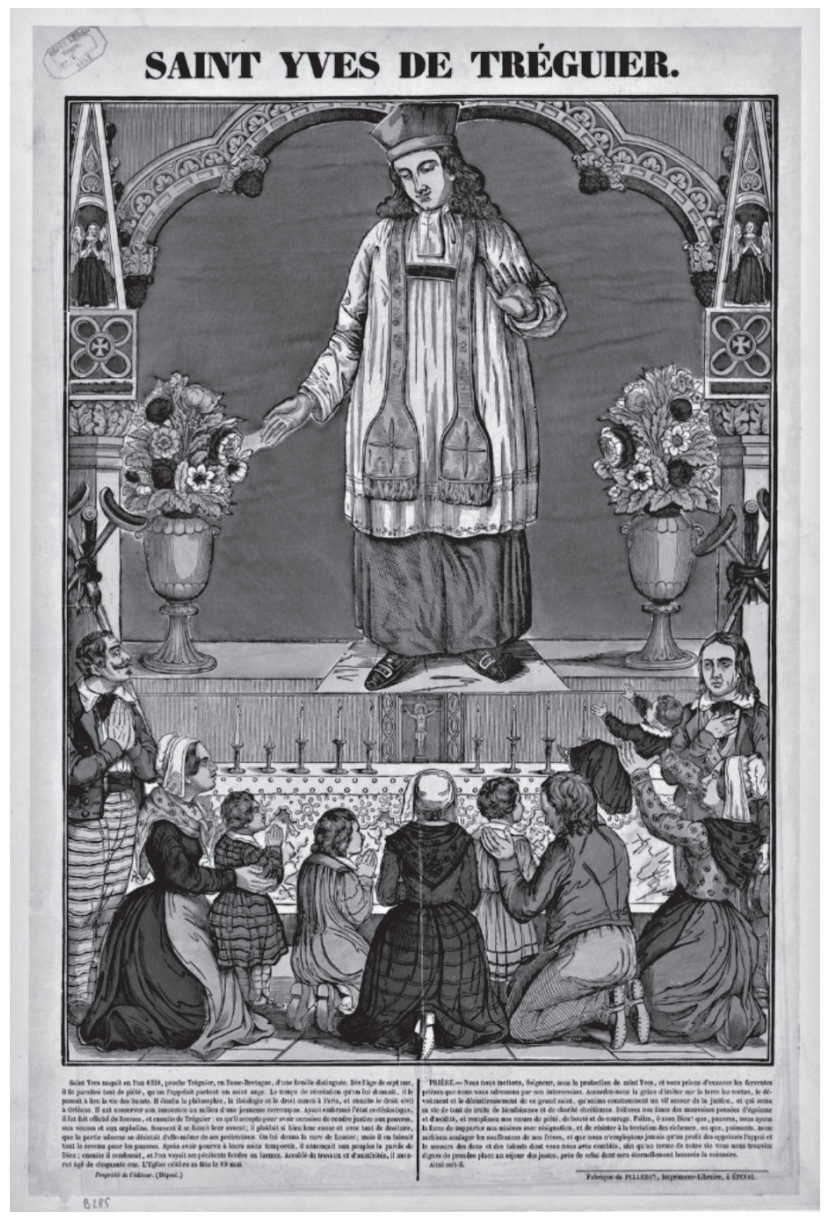

\section{Figura 1}

Fuente: Saint Yves de Tréguier : [estampe], Editeur : Pellerin, 1852. Grabado sobre madera en color, 60 x $40 \mathrm{~cm}$. Bibliothèque nationale de France, département Estampes et photographie, fol-lifol-li-59 (4). Imagen en formato JPG, de dominio público. Disponible en: <http://gallica.bnf.fr/ark:/12148/btv1b69380999>. Repositorio <http://catalogue.bnf.fr/ark:/12148/cb41225563v>, perteneciente a la colección Recueil. Images d'Epinal de la Maison Pellerin, t. 4, 1851-1854. Disponible en: <http://catalogue.bnf.fr/ark:/12148/ cb412677522>. 


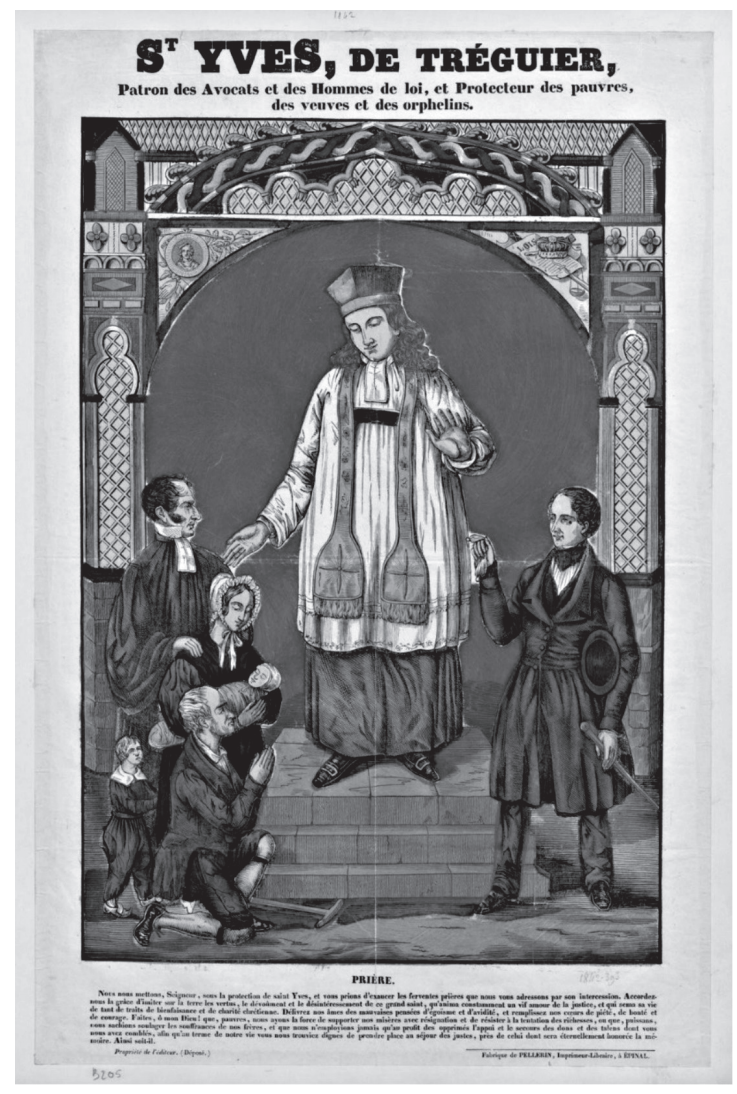

Figura 2

San Yves, de Tréguier, patrón de los abogados y hombres de ley, protector de los pobres, las viudas y los huerfanos. Fuente:

St Yves, de Tréguier, Patron des Avocats et des Hommes de loi, et

Protecteur des pauvres, des veuves et des orphelins : [estampe], Fabrique de Pellerin, Imprimeur-libraire à Epinal [1842], grabado sobre Madera con color, 61 x $40 \mathrm{~cm}$, Bibliothèque nationale de France, département Estampes et photographie, fol-lifol-li--59 (3). Imagen en formato jpg de dominio publico. Disponible en: <http://gallica. bnf.fr/ark:/12148/btv1b6938012c>. Repositorio: <http://catalogue. bnf.fr/ark:/12148/cb412255588>, perteneciente a la colección Recueil. Images d'Epinal de la Maison Pellerin. Tome 3, 1842-1850. Disponible en: <http://catalogue.bnf.fr/ark:/12148/cb41256172k>. 


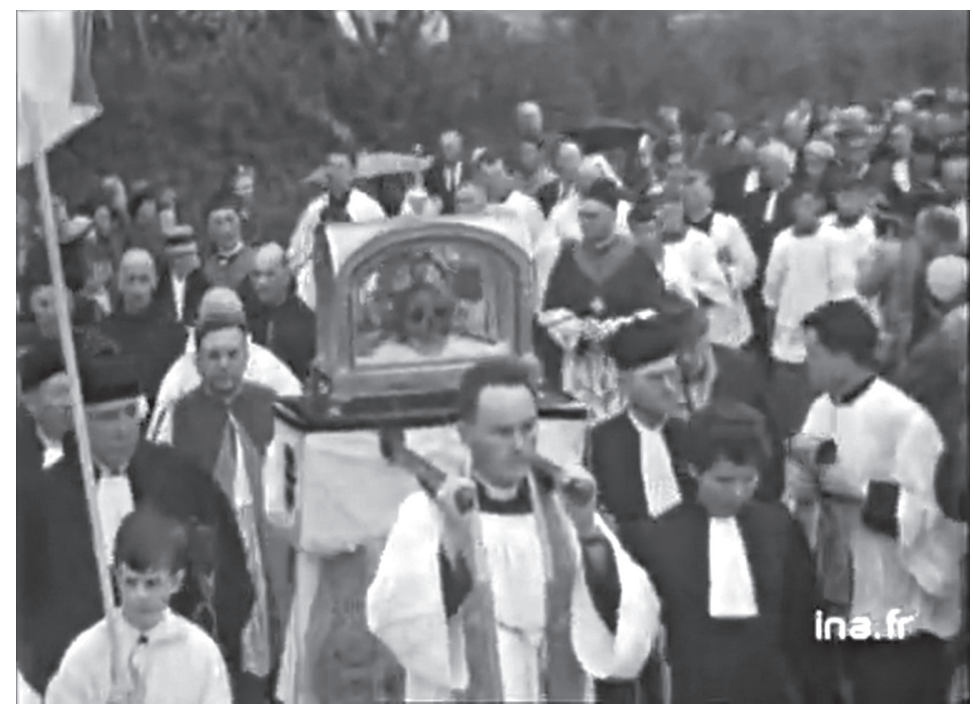

Figura 3

Treguier: Pardon de Saint Yves. Captura de pantalla. Fuente: Office national de radiodiffusion télévision française, "Treguier: Pardon de Saint Yves", Bretagne actualités, 20 de mayo de 1964. Disponible en: <http://www.ina.fr/video/RYC9710315504>.

tancia de los seglares masculinos en la fiesta, justo en la época en que el Concilio Vaticano II se planteaba el problema del papel de los laicos en la Iglesia.

Diez años después, en 1974, en un programa de televisión a color, las mujeres hacen su aparición en la procesión al cargar la cabeza del santo, lo cual muestra un cambio significativo en el papel de ellas dentro de la Iglesia.

En el siglo XXI ya no son sólo los medios de comunicación los que graban las ceremonias del perdón: los fieles mismos, empleando las nuevas tecnologías, empiezan a generar la memoria audiovisual del evento. En este sentido, están naciendo nuevas iniciativas en la World Wide Web. Una de las más interesantes es el Fondo san Yves, una asociación civil enfocada a la promoción de la figura de San Yves y la organización de los perdones. 


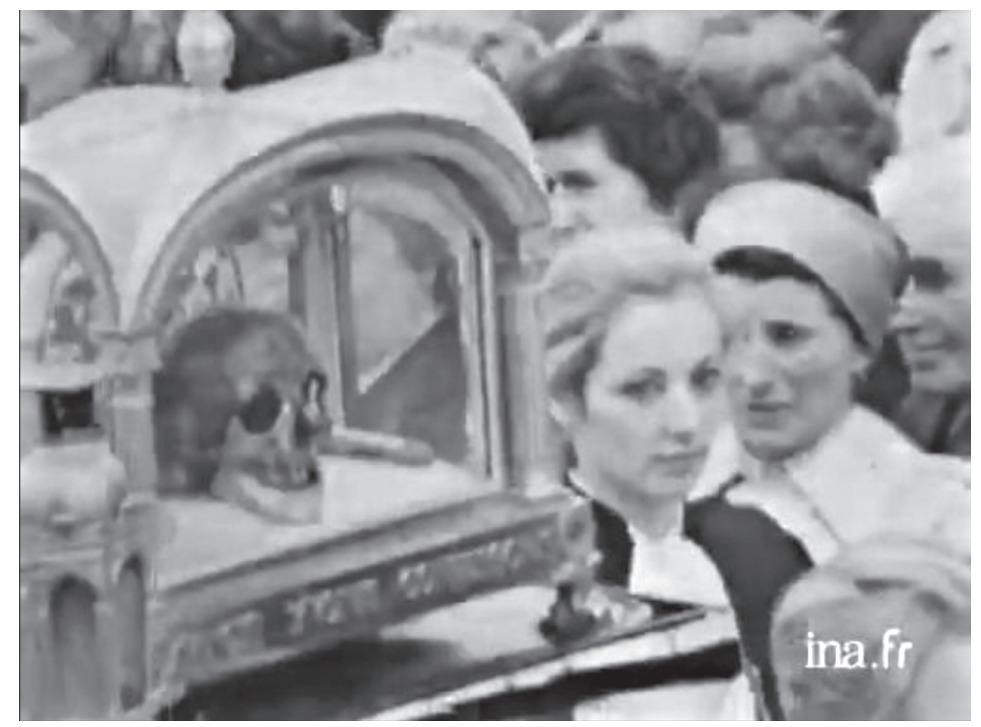

Figura 4

Captura de pantalla del video "Le pardon de saint Yves à Tréguier". Fuente: Office national de radiodiffusion télévision française, "Le pardon de Saint Yves a Tréguier", Bretagne actualités, 19 de mayo de 1964. 1 minuto 17 segundos. Disponible en: <http://fresques.ina.fr/ouest-en-memoire/ fiche-media/Region00023/le-pardon-de-saint-yves-a-treguier.html>.

Hoy día, el culto a san Yves sigue siendo uno de los más tradicionales de la Francia católica y del catolicismo de Bretańa. En un país con reputación de laicidad y secularización social, basta ver los millares de personas que asisten al perdón, ya sea como fieles o como observadores, para darse cuenta de la actualidad del fervor religioso de un santo no solamente regional sino también nacional. ${ }^{54}$

${ }^{54}$ Los periódicos de Bretaña, en particular el famoso Ouest-France, le dedica no sólo ediciones impresas al acto sino también aprovecha su edición digital para difundir las imágenes de éste: <https://www.ouest-france.fr/bretagne/treguier-22220/ treguier-la-foule-fidele-au-pardon-de-saint-yves-5007782>. Se puede consultar directamente el adobe spark del perdón de 2017 en : <https://spark.adobe.com/ page/ch70qYTFocIPx/?ref=https $\% 3 \mathrm{~A} \% 2 \mathrm{~F} \% 2 \mathrm{Fspark}$.adobe.com $\% 2 \mathrm{Fpage} \%$ 2CH70qYTFOCIPx\%2Fembed.html\&embed_type=overlay\&context=expand $>$. 


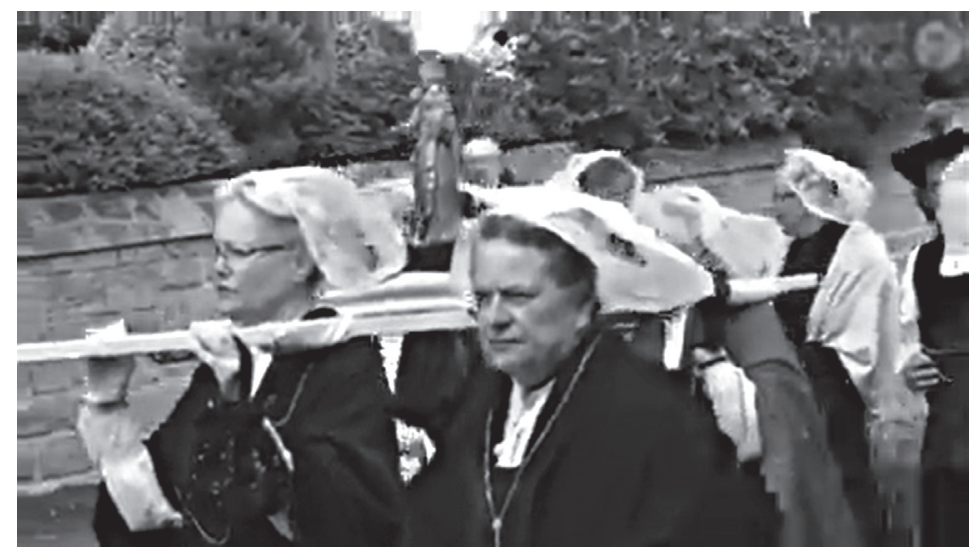

Figura 5

Captura de pantalla del video "Le pardon de Saint Yves, à Tréguier". Fuente: "Le pardon de Saint Yves, à Treguier", Ouest France, 22 de mayo de 2016. Disponible en: <https://www.youtube.com/ watch? $=x E N l Q r X d q d g>$.
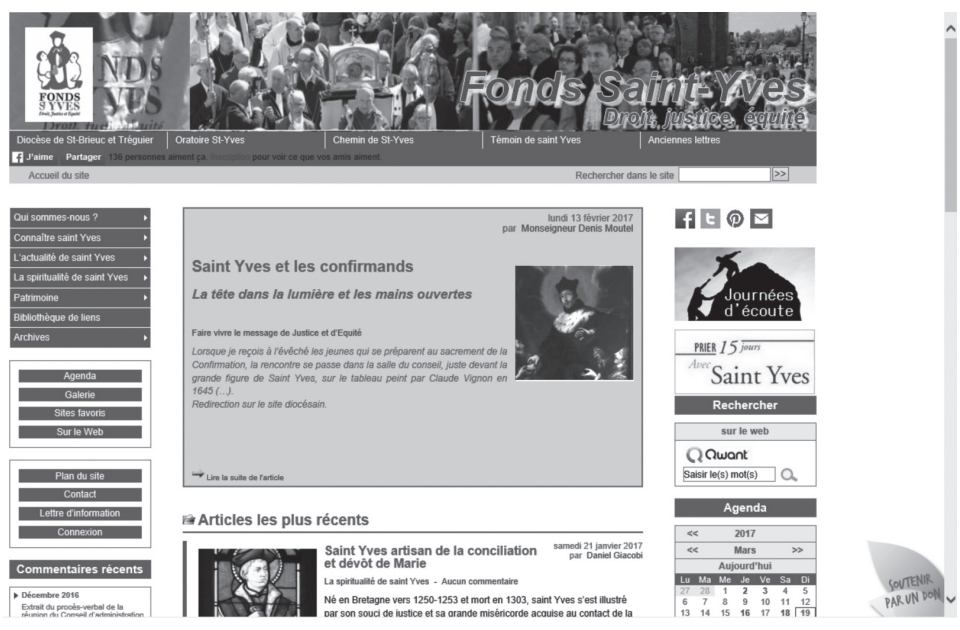

\section{Figura 6}

La página principal del Fonds St Yves. ${ }^{55}$

${ }^{55}$ Creado en 2013, el sitio permite contar con la intercesión de san Yves por medio de rezos específicos para las familias, los estudiantes, los litigantes, etc. 
Los estudiosos, que a la fecha realizan trabajos y publicaciones sobre san Yves, muy poco lo hacen a través de libros impresos, ya que es más fácil encontrar información en línea. ${ }^{56}$ Sin embargo, a pesar de su presencia en Twitter y Facebook, esta iniciativa está lejos de tener el éxito en espacios que manifiesten la promoción de nuevos santos, como ocurre con la madre Teresa de Calcuta.

\subsection{Santa Teresa de Calcuta}

El caso de la madre Teresa de Calcuta es destacable para quien se interesa en los procesos de canonización iniciados en el siglo xx. Teresa, quien fue reconocida beata por Juan Pablo II en 2003 y canonizada por el papa Francisco en 2016, cuenta con una popularidad indiscutible dentro de las redes sociales. Así, por ejemplo, los perfiles de Facebook "Madre Teresa de Calcuta/Mother Teresa of Calcuta" cuentan con 799650 "me gusta" y 772666 seguidores; el perfil "Mother Teresa" tiene 787316 "me gusta", ${ }^{57}$ mientras que la página del Centro Madre Teresa de Calcuta ("Madre de Teresa de Calcuta, @madreteresadecalcuta”), promovida por los Misioneros por la Vida para una Iglesia sin Fronteras, cuenta con 233144 "me gusta” y 229652 seguidores. ${ }^{58}$ Está página de Facebook se encuentra vinculada con el sitio web del centro Mother Teresa of Calcuta, ${ }^{59}$ disponible en inglés, alemán, español, fran-

y dejar intenciones para el santo: <http://fonds-saintyves.fr/>. Su misión: “emprender, apoyar cualquier actividad de interés general que permita perennizar la herencia universal legada por san Yves, sacerdote, juez, abogado y amigo de los pobres".

${ }^{56}$ Jean-Paul Le Guillou, Saint Yves - Enquête de canonisation. Ceux qui l'ont connu témoignent. Ceux qu'il a guéri racontent, Saint Brieuc, Imp. Teck Impressions, 1989. Disponible en <https://fonds-saintyves.fr/Saint-Yves-Enquete-de-canonisation.html>.

${ }^{57}$ En 2016 se contaba con 799650 "me gusta” y 772666 seguidores. En 2018 se percibe una baja del número: en octubre había 797 mil "me gusta” y 771 mil seguidores.

${ }^{58}$ En octubre de 2018 el número de "me gusta" aumentó ligeramente, pasando a 234771 personas y el número de seguidores llegó a 231420.

${ }^{59}<$ http://www.motherteresa.org>. 
cés, italiano y portugués, y ofrece un interesante vínculo con un espacio informativo sobre todo el proceso de canonización.

La figura de santa Teresa de Calcuta tiene un centenar de páginas de Facebook relacionadas su nombre, desde escuelas y organismos religiosos hasta centros de maternidad, oficinas de mercadotecnia y perfiles de figuras públicas. La libertad de producir contenidos en las redes impide cualquier forma de control institucional por parte de la Iglesia. La página de Facebook con más seguidores es, sin embargo, la vinculada con el sitio oficial del Centro Madre Teresa. Su éxito es tal que fue víctima de fraude cibernético: un grupo de personas promovió una falsa campaña de donación a su nombre. Ello provocó que los administradores del sitio enviaran un comunicado oficial para alertar a los fieles. ${ }^{60}$

Otro tema de sumo interés promovido en la página es la explicación de la temática de los santos, los beatos y sus reliquias. ${ }^{61}$ El sitio, que dedica un espacio a explicar qué son estas últimas y los peligros de la simonía, ofrece la posibilidad de obtener piezas genuinas a través del correo tradicional.

\section{Reliquias de la Beata Teresa}

Si desea recibir una reliquia de la beata Teresa de Calcuta, puede comunicarse con la Oficina de Postulación por correo electrónico a relic@motherteresa.org (que nos proporciona su dirección postal para que podamos enviarle una) o escribir a:

Postulator, 524 West Calle Primera, Suite \#1005N, San Ysidro CA 92173, USA.

The Vice-Postulatrix, c/o 54A, A. J. C. Bose Road, Calcutta 700016, INDIA.

Postulation Office, c/o Piazza S. Gregorio al Celio, 2, 00184 Rome, ITALY.

60 "Fraudulent e mail", Mother Theresa Center. Disponible en: <http://www.motherteresa.org/08_info/e-mails.html>.

${ }_{11}$ "Eveneración [sic] de los santos, beatos y sus reliquias", Mother Theresa Center. Disponible en: <http://www.motherteresa.org/espanol/09_reliquias/vENERATION. html>. 
Hay numerosos sitios comerciales en la red vendiendo "reliquias" de la beata Teresa, en algunos de sus anuncios publicitarios incluyen la frase "del Vaticano". Sin la autentificación del Postulador, ninguna reliquia tiene la garantía de autenticidad y debería ser considerada como dudosa y sospechosa. ¡Además, la venta de reliquias sagradas está de modo terminante prohibida por la Iglesia! ${ }^{62}$

En este sentido, es claro que el halo y poder de atracción de la madre Teresa rebasa los límites de la Iglesia institucional. Su peso es tal que miles de páginas y videos están dedicados a la santa. Entre esos numerosos videos, el Centro Madre Teresa optó por publicar diez en los que se puede escuchar el mensaje de la religiosa en su propia voz, tanto en conferencias como en espacios públicos donde su labor estaba siendo reconocida. También se compila una veintena más de videos tomados de YouTube. ${ }^{63}$

Sin embargo, no toda la narrativa en torno a Teresa de Calcuta es hagiográfica. Algunos análisis contemporáneos exploran las huellas de procesos depresivos en sus obras. ${ }^{64} \mathrm{El}$ psiquiatra Taylor Williams, por ejemplo, en el libro Ven, sé mi luz-editado por Brian Kolodiejchuk-65 analiza las cartas escritas por la madre Teresa a su confesor, publicadas en 2007, para construir un caso clínico. Williams ve en los escritos de la madre Teresa la narrativa de una enfermedad mental que requería de un tratamiento psiquiátrico:

62 "Reliquias", Mother Theresa Center. Disponible en: <http://www.motherteresa. org/espanol/09_reliquias/RELICS.htm>.

63 "Video", Mother Theresa Center. Disponible en: <http://www.motherteresa. org/tube/1vid_eng.html>. Desde la página principal se puede consultar también la sección "Creative presentations" de <http://motherteresa.org/layout.html $>$.

${ }^{64}$ S. Taylor Williams, "Illness Narrative. Depression, and Sainthood: An Analysis of the Writings of Mother Teresa”.

${ }^{65} \mathrm{~S}$. Taylor Williams trabajó la versión en inglés de este libro: Brian Kolodiejchuk (ed.), Mother Teresa: Come Be my Light_-The Private Writings of the Saint of Calcutta, Nueva York, Doubleday Religion, 2007. 
En el caso de la madre Teresa, nunca sabremos si su "oscuridad" era una depresión médica que hubiese tenido que ser tratada con medicación o psicoterapia. Sabemos que su miseria no respondió sólo a la consejería pastoral, que la motivó a escribir sobre sus sentimientos, sus rezos, su labor y sus dudas personales. En un esfuerzo para poner el sufrimiento de la madre Teresa en un contexto espiritual (y quizá de santidad) se debe tomar en cuenta una consideración biológica: la noche negra de la madre Teresa fue una enfermedad mental y sus confesiones fueron una narrativa de su enfermedad. Si ello fuese el caso, podemos decir entonces que la madre Teresa sufrió innecesariamente y que un tratamiento psiquiátrico hubiese podido restaurar su ánimo. ${ }^{66}$

Este estudio lleva a Williams a afirmar que la madre Teresa podría reemplazar a santa Dimpna como patrona de las enfermedades mentales. "Si en un futuro, un Papa declara a la ahora beatificada Madre Teresa como una santa, quizá sería como patrona para todos aquellos que sufren de depresión, pues como ella mismo lo sugirió: 'Si alguna vez me convierto en una santa, por seguro seré una de la oscuridad'". ${ }^{67}$

Así, este análisis de las cartas íntimas de Teresa a su confesor, en lugar de abonar a la hagiografía de la monja albanesa, presenta la crisis psicológica de una mujer al borde de la depresión. Lo que para los fieles aparece como muestra de una fe incuestionable, podría ser una enfermedad mental.

Por otro lado, la publicación de sus cartas permite también apreciar, como en pocos casos, el diálogo y las tensiones entre la apariencia externa de la fe y las dudas internas de una santa. El confesor de la madre Teresa respetó en vida de la religiosa la confidencialidad de las misivas; sin embargo, al publicarlas después de su muerte, ha colaborado a la construcción de la imagen de una santa "más humana". ${ }^{68}$

${ }^{66}$ Williams, "Illness Narrative...", op. cit., pp. 294-295.

${ }^{67}$ Ibidem, p. 297.

${ }^{68}$ Rachel Wagner, Godwired Religion Ritual and Virtual Reality, pp. 217-219. 
Un estudio de Daniel Kline propone una continuidad entre las hagiografías medievales y las digitales en los casos de Lady Di y de la madre Teresa: "A pesar de que el internet abarca las respuestas populares al espectro de la mayoría de los problemas de hoy, cada sitio representa una amalgama de códigos culturales en la encarnación de un momento histórico particular, justo el tipo de efemérides que los especialistas usan para contextualizar el periodo medieval". ${ }^{69}$ Este estudio, que se llevó a cabo justo tras la muerte de esas dos figuras públicas en el marco de una clase sobre mujeres en la Edad Media, nos muestra, a la distancia, la transformación del internet en sí: las 47 páginas web encontradas en Yahoo en 1997 distan mucho de las más de los 18700000 que hoy tienen alguna relación con la santa (desde artículos, twitter, videos, hasta sitios dedicados a la monja) y los 30500 sitios relativos a la santa que existen hoy día, si bien no todos están relacionados con ella. Pero, más allá de este crecimiento cuantitativo de la hagiografía digital, lo interesante en el estudio de Klein es el análisis de las diferentes narrativas que, a su juicio, acercan la figura de la madre Teresa a la de los ascetas y la de Diana a la de los mártires:

Primero, y particularmente en el caso de la princesa Diana, los estudiantes se impresionaron con la fascinación mórbida hacia los "detalles de su muerte". Aquí encontramos un contraste interesante: la muerte de la princesa Diana nos sorprendió en su aspecto repentino y violento; la muerte de la madre Teresa nos entristeció por su prolongación e inevitabilidad. Como en el caso del fallecimiento de numerosos santos píos en el pasado, la muerte de Teresa fue percibida como un final natural para su vida de servicio y autonegación, mientras que el fin violento de Diana reflejó la muerte súbita y caprichosa de una figura real o pía cortada en la flor de la vida. La muerte de la monja refleja las historias de vida de los ascetas piadosos, mientras que el fa-

${ }^{69}$ Daniel T. Kline, "Digital Hagiography: Princess Diana, Mother Teresa, and Medieval Women in Cyberspace", p. 95. 
llecimiento de la princesa remite a los recuentos gráficos de los antiguos mártires magullados y ensangrentados por su fe. ${ }^{70}$

Más allá de las figuras en sí, hay una continuidad entre las narrativas medievales y las de la edad del internet. En el experimento llevado a cabo en clase, los estudiantes de Kline se dieron cuenta de que tanto el periodo medieval como el moderno "comparten la necesidad de determinar la viabilidad cultural de una potencial vida de santo al averiguar o hasta construir el estado del alma de una persona, su esencia subjetiva al momento de su muerte. Se piensa que los verdaderos santos irradian una especie de 'aura', una penumbra sagrada, una esencia o incorruptibilidad que atestigua lo sagrado del santo". ${ }^{71}$

Este tipo de estrategias se emplea a la fecha en diferentes sitios de internet que promueven no sólo a santos católicos, sino también a algunos santos cívicos, ${ }^{72}$ es decir, personas cuyas vidas son idealizadas y reescritas con recursos similares a los de la hagiografía católica. Las nuevas narrativas que borran los aspectos más cuestionables de personas como Lady Di, Steve Jobs o Nelson Mandela no parecen tan alejadas de las recopilaciones de vid暦 de santos de la Legenda Aurea o de la South English Legendary. Si se parte del pensamiento de Jean Jacques Rousseau en El contrato social y de las reflexiones de Emilio Gentile, ${ }^{73}$ no es sorprendente que los sectores más secularizados de la sociedad utilicen con fines políticos e ideológicos el género de las vidas ejemplares para exaltar a personajes que, por su vida y obra, han provocado en varios de sus contemporáneos admiración y casi veneración. ${ }^{74}$

\footnotetext{
${ }^{70}$ Ibidem, p. 96.

${ }^{71}$ Ibidem, p. 97.

${ }^{72}$ Entre esos santos cívicos, algunos fueron precursores de las nuevas tecnologías, como es el caso de Steve Jobs. Véase Antonio Spadaro, Cybertheology. Thinking Christianity in the Era of the Internet, pp. 108-109.

${ }^{73}$ Emilio Gentile, Politics as Religion.

${ }^{74}$ Además de los ejemplos mencionados arriba, otros personajes cuya vida recibe un tratamiento similar actualmente son los astros del futbol contemporáneo,
} 
En la época del estudio de Kline era imposible imaginar todas las posibilidades que ofrecen hoy a la hagiografía, la Web 2.0 y la democratización de la creación de contenidos. Ya no solamente se trata de páginas de internet, sino también de otros productos creativos como los perfiles de Facebook e Instagram o la creación de videos, frutos de la posmodernidad y del "mundo líquido". 75 Se dice mucho que el mundo actual es la era de la información, pero lo es también de la superficialidad. El número de tuits, la cantidad de información producida, crean ruido. De acuerdo con Bauman, el estado fluido y volátil de la sociedad actual lleva a un cuestionamiento de los valores tradicionales al mismo tiempo que genera incertidumbre por la vertiginosa rapidez de los cambios que han debilitado los vínculos humanos y a veces ofrece un modo de interacción mediado por pantallas como las de los teléfonos celulares.

Las hagiografías digitales que están en el mismo mundo y espacio que Twiter, Instagram y Facebook ofrecen, al contrario, un espacio de tranquilidad. A veces estáticas, tienden a promover textos e imágenes clave que proponen al visitante un espacio virtual de regocijo y paz. Los videos son más profundos, los pensamientos ofrecen vínculos continuos a textos y reflexiones, y si bien las páginas van actualizando los rezos y los fieles van compartiendo sus emociones y experiencias, la representación del santo, más que transformada por la era digital, parece sufrir un proceso de actualización. La historia del santo es similar de una página a otra, es como si la Legenda aurea no se transformara, sino que se "subiera" en un formato digital, con la misma narrativa y uno que otro trato más contemporáneo, pero la edificación de los fieles es la misma. La historia se cuenta, se narra de la misma manera; solamente se cambia el formato sin transformar la narrativa. No existe

como Cristiano Ronaldo, Neymar Junior o Lionel Messi. Será la duración de su aura dorada la que determinará si llegarán al santoral laico y compartirán espacios simbólicos con el rey Pelé o el Pelusa, Diego Maradona.

${ }^{75}$ Zygmunt Bauman, Vida líquida. 
un proceso de renovación narrativa, se sigue el modelo analógico de la tradición de los santos en lugar de preferir un nuevo formato reticular. Este punto es fundamental, porque las narrativas de santidad en la era digital siguen la lógica narrativa de los libros, y no la lógica reticular de las nuevas tecnologías. A veces, la limitante también está vinculada con que el fiel que promueve una página web no es por fuerza un diseñador, sino un fiel deseoso de dar a conocer en la red la historia y la buena nueva a través de la intercesión del santo de su devoción. Resulta entonces fundamental hacer preguntas a los textos que permitan revelar sus aspectos ideológicos y contextuales para intentar explicar el proceso de su narrativa y el particular tratamiento del santo en cuestión. ${ }^{76}$

En palabras de Kline:

La respuesta increíble del público a las muertes de la princesa Diana y la madre Teresa pueden ser consideradas como una forma de devoción pública equiparable al afecto dado a los santos medievales y, en el marco de una comparación entre los santos modernos y los medievales, ofrece tanto a medievalistas como a otros profesionales de la literatura una ocasión pedagógica importante para la investigación y análisis de los discursos y de la creación cultural de la identidad. ${ }^{77}$

Para Spadaro: "en la Web, la Iglesia esta llamada no solamente a ser difusora de contenido, sino que debe ser 'testigo' en el contexto de relaciones más amplias. [...] Los humanos, quienes hoy han entrado en conexiones que los unen al mundo y a otras personas, tienen un 'aura electrónica' que en el mundo digital constituye la forma de dar lo que, en el mundo tradicional, se entiende por testimonio". ${ }^{78} \mathrm{Al}$ respecto, Spadaro opina que se deben escuchar las palabras de Benedicto XVI: "Una pastoral en el

${ }^{76}$ Kline, “Digital Hagiography...”, op. cit., p. 105.

${ }^{77}$ Ibidem, p. 109.

${ }^{78}$ Spadaro, Cybertheology, op. cit., pp. 49-50. 
mundo digital está llamada a tener en cuenta también a quienes no creen y desconfían, pero que llevan en el corazón los deseos de absoluto y de verdades perennes, pues esos medios permiten entrar en contacto con creyentes de cualquier religión, con no creyentes y con personas de todas las culturas". ${ }^{79}$

El tema es tan problemático - por el negocio que se genera alrededor de las reliquias- que en 2017 la Congregación para las causas de los santos estableció unas instrucciones al respecto. ${ }^{80}$ El Sumo Pontífice aprobó esta Instrucción el 5 de diciembre del mismo año y el texto fue publicado en L'Osservatore Romano el 17 de diciembre, con entrada inmediata en vigor.

El reto para el mundo católico es no caer en la simonía o en el negocio de venta y compra de reliquias, sean éstas falsas o genuinas. En este sentido es que los casos tanto de san Yves como de la santa madre de Calcuta muestran cómo las narrativas digitales sólo actualizan las hagiografías existentes pero no las desplazan.

\section{Conclusiones}

En la era de la Web 2.0 la promoción de las nuevas figuras de santos, mártires y beatos rebasa la simple voluntad institucional. Los creyentes se apropian de las nuevas figuras de santos sin consultar a la institución de la Iglesia católica. Las relaciones en torno a las prácticas religiosas y la nueva era digital permiten ver cómo un espacio que nació laico -como el internet- se está sacralizando a través de las prácticas de los fieles. Este fenómeno no solamente

\footnotetext{
${ }^{79}$ Benedicto XVI, "Mensaje del Santo Padre Benedicto XVI, para la XLIV Jornada Mundial de las comunicaciones sociales 'El sacerdote y la pastoral en el mundo digital: los nuevos medios al servicio de la Palabra”, domingo 16 de mayo de 2010. Disponible en: <https://w2.vatican.va/content/benedict-xvi/ es/messages/communications/documents/hf_ben-xvi_mes_20100124_ 44th-world-communications-day.html>.

80 "Reliquias en la Iglesia: Autenticidad y conservación". Disponible en: <http:// www.vatican.va/roman_curia/congregations/csaints/documents/rc_con_ csaints_doc_20171208_istruzione-reliquie_sp.html>.
} 
habla de nuevas prácticas, sino que obliga también al historiador a revalorar el papel de las fuentes documentales, la información del medio histórico, la necesidad de analizar los documentos y la posibilidad de ampliar el acervo histórico existente con archivos y fondos particulares. Este estudio sirve para poner en evidencia la dificultad que experimenta la Iglesia Católica Apostólica y Romana al tratar de adaptarse a un mundo que no comparte la necesidad de la verdad revelada. Permite también mostrar el choque entre el peso de la tradición de la Iglesia y las posibilidades que están abriendo las nuevas redes sociales, pues en ellas, fuera de las barreras institucionales, cada lego adquiere una cierta cuota de poder mediante sus publicaciones.

Conviene, sin embargo, relativizar la transformación de la hagiografía vinculada con las nuevas formas de narrativas digitales. La utilización de un medio secular como el internet para emprender la tarea evangelizadora de la Iglesia no es nuevo; por el contrario, es una muestra más del dinamismo de la Iglesia católica y responde a una tradición iniciada desde el siglo xix con el uso de la prensa como vía para difundir la buena nueva y las preocupaciones terrenales y espirituales de la Santa Sede. Lo mismo ha pasado con la cinematografía, la radio y la televisión, empleadas por el catolicismo para la promoción de la fe. Sin embargo, la aparición del internet y el desarrollo de la Web 2.0 están generando cambios en la forma en la que se escriben las hagiografías. La interacción con nuevos medios de comunicación permite ver que la Iglesia católica y en particular la Santa Sede han abrazado las nuevas herramientas tecnológicas para renovar y actualizar sus narrativas más que para transformarlas radicalmente.

La presente reflexión intenta también apuntar la necesidad de diseñar nuevos instrumentos para lograr un intercambio con el promotor de la causa y los animadores virtuales de las redes analizadas. Cada vez más los estudiosos tendrán que interesarse en el seguimiento de prácticas etnohistóricas que hoy toman senderos tanto tradicionales como digitales. En específico, un trabajo pos- 
terior debería recurrir a una visión más cuantitativa y unificar algunos elementos de análisis de esos estudios de caso para rastrear recurrencias y distinciones en torno a las representaciones graficas difundidas en los diferentes portales; también debería realizar una averiguación más cualitativa en torno a quiénes son los animadores de las redes, cuáles son las opciones de los diseñadores y quiénes financian a los portales. Asimismo, será necesario dar un seguimiento en lapsos largos de tiempo al número de visitas para tratar de determinar el éxito o fracaso de las narrativas mediante un enfoque mixto que retome los metadatos de los sitios, pero que también se acerque a los web masters de las iniciativas.

\section{Bibliografía}

Ackerman Smoller, Laura. "From Authentic Miracles to a Rhetoric of Authenticity: Examples from the Canonization and Cult of St. Vincent Ferrer", Church History, 1 de diciembre de 2011. Disponible en: <http:// www.readperiodicals.com/201112/2535894551.html>.

Acta Sanctorum. Disponible en: <http://acta.chadwyck.com/?instit1=T173712\&instit2=V29MW3P5Z6>.

Aigrain, René. L'Hagiographie, ses sources, ses méthodes, son histoire, París, Bloud et Gay, 1953.

Barboso, Jesús Martín. Efimero y trascendente. Lo sagrado y los medios de comunicación, Lima, Fondo Editorial de la Universidad Antonio Ruiz de Montoya, 2009.

Bartlett, Robert. Why Can the Dead Do Such Great Things?: Saints and Worshippers from the Martyrs to the Reformation, Princeton, Nueva Jersey, Princeton University Press, 2013. Disponible en: <http://www.jstor. org/stable/j.ctt46n3wb>.

Baudot, Dom. Dictionnaire d'hagiographie mis à jour à l'aide des travaux les plus récents, París, Librairie Bloud et Gay, 1925.

Bauman, Zygmunt. Vida líquida, Barcelona, Paidós, 2006. (Estado y Sociedad, 143).

Boardman, Steve. "The Survey of Dedications to Saints in Medieval Scotland”, The Innes Review, vol. 59, núm. 2, Autumn 2008, pp. 189-191. DOI: $10.3366 / \mathrm{E} 0020157 \mathrm{X} 08000280$. 
John Davies y Eila Williamson. "Survey of Dedications to Saints in Medieval Scotland". Database. School of History, Classics and Archaeology: Scottish History, The University of Edinburgh, Scotland, 2006. Disponible en: <http://webdb.ucs.ed.ac.uk/saints/>.

Brown, Peter. "The Rise and Function of the Holy Man in Late Antiquity", The Journal of Roman Studies, núm. 61, 1971, pp. 80-101. DoI: $10.2307 / 300008$.

Bynum, Caroline Walker. Holy Feast and Holy Fast: The Religious Significance of Food to Medieval Women, Berkeley, University of California Press, 1987. - Jesus as Mother: Studies in the Spirituality of the High Middle Ages, Berkeley, University of California Press, 1982.

Carpio Pérez, Amílcar. "Los procesos de santidad: la construcción de una devoción", tesis de Doctorado en Humanidades (Historia), México, UAM-Iztapalapa, 2015.

Cassard, Jean-Christophe y Georges Provost (dirs.). Saint Yves et les Bretons: Culte, images, mémoire (1303-2003), nueva ed. [en línea], Rennes, Presses universitaires de Rennes, 2004 (2016). Disponible en: <http:// books.openedition.org/pur/22388>. DoI: 10.4000/books.pur.22388.

Catholic University of America Press. "Part I: The Auxiliary Sciences", The Catholic Historical Review, vol. 1, núm. 3, oct., 1915, pp. 359-363. Disponible en Jstor. Stable: <http://www.jstor.org/stable/25011359>.

Decherf, Jean-Baptiste y Jean-Philippe Plez. "Les saints et la sainteté. Histoires, concepts, méthodes", Conserveries mémorielles, \#14, 2013. Disponible en: <http://cm.revues.org/1505>.

Delgado, Álvaro. "A Beacon in a Time of Darkness", New Oxford Review, vol. 84, núm. 1, January 2017, pp. 28-31. Academic Search Complete, EBSCohost.

Dunn, Mary. “'But an Echo'?: Claude Martin, Marie de l'Incarnation, and Female Religious Identity in Seventeenth-Century New France", Catholic Historical Review, vol. 100, núm. 3, 2014, pp. 459-485. MLA International Bibliography, EBscohost.

Einstein, Mara. Brands of Faith: Marketing Religion in a Commercial Age, Nueva York, Routledge, 2008

Eming, Jutta. "Chopped Up, Grilled and Shrunken to the Size of a Hedgehog: The Bodies of Saints in Medieval Hagiography and in Thomas Mann's Der Erwählte", Seminar: A Journal Of Germanic Studies, vol. 46, núm. 2, May 2010, pp. 146-160. MLA International Bibliography, EBscohost. 
Foltz, Bruce V. y Peter L Schweitzer. "Pope Francis and the perils of double truth", Christian Bioethics, vol. 21, núm. 1, April 2015, pp. 89-108. ATLA Religion Database, EBscohost.

Cheong, Pauline Hope, Peter Fischer-Nielsen, Stefan Gelfgren y Charles Ess (eds.). Digital Religion, Social Media, and Culture: Perspectives, Practices, and Futures, Nueva York, Peter Lang, 2012.

Horsfield, Peter, Mary E. Hess, Adán M. Medrano y Juan Carlos Henriquez (eds.). Medios y creencia. Perspectivas culturales del cristianismo en el entorno mediático, México, Universidad Iberoamericana/Plaza y Valdés, 2007.

Gentile, Emilio. Politics as Religion, Princeton, Nueva Jersey, Princeton University Press.

Kline, Daniel T. "Digital Hagiography: Princess Diana, Mother Teresa, and Medieval Women in Cyberspace”, College Literature, vol. 28, núm. 2, Spring 2001, 92-117. Academic Search Complete, EBscohost.

Kuefler, Mathew. The Making and Unmaking of a Saint: Hagiography and Memory in the Cult of Gerald of Aurillac, Filadelfia, University of Pennsylvania Press, 2014.

La Borderie, Arthur Le Moyne de. "Les monuments originaux de l'histoire de saint Yves : rapport à Mgr l'évêque de Saint-Brieuc et Tréguier / par Arthur de La Borderie,...," Collections numérisées, Université de Rennes 2. Disponible en : <http://bibnum.univ-rennes2.fr/items/show/347>.

La Roncière, Charles Germain Marie Bourel de. Saint Yves (1253-1303), París, Victor Lecoffre, 1901.

López Menéndez, Marisol. Miguel Pro: Martyrdom, Politics, and Society in Twentieth-Century Mexico, usA, Lanham, 2016. McDonell, James y Frances Tampiets (eds.). Comunicating Faith in a Technological Age, England, St Paul Publication, 1989.

O’Connell, Gerard. "Money and Saint-Making”, America 214, núm. 12, (April 4, 2016). Academic Search Complete, EBscohost (accessed March 13, 2017).

Philpott, Daniel. "Modern Martyrs”, America, vol. 207, núm. 14, November 12, 2012, pp. 12-18. Academic Search Complete, EBscohost.

Provost, Jacques. "Le rituel du pardon de Saint-Yves ( $\mathrm{XvI}^{\mathrm{e}}-\mathrm{Xx}^{\mathrm{e}}$ siècles)", en Jean Christophe Cassard y George Provost, Saint Yves et les Bretons: Culte, images, mémoire (1303-2003), Rennes: Presses Universitaires de Rennes, 2004, pp. 257-272.

Rio, Bernard. Sur les chemins des pardons et pèlerinages en Bretagne, París, Le Passeur, 2015. 
Smoller, Laura A. The Saint and the Chopped-Up Baby: The Cult of Vincent Ferrer in Medieval and Early Modern, Europe, Ithaca, NY, Cornell University Press, 2014.

"Siete nuevos santos para la Iglesia", Humanitas, vol. 21, núm. 83, oct. 2016, pp. 596-600. (07172168) [serial on the Internet]. Disponible en: Fuente Académica.

Solis, Yves. “¿Camino a la santidad en épocas digitales?: El caso de Luis María Gonzaga Martínez Rodríguez”, en Marisol López Menéndez (coord.), Mártires, santos, patronos. Devociones y santidad en el México del siglo XX, México, Uia, 2016, pp. 81-102.

- "De la centralización romana a la descentralización de las redes sociales: la promoción de la figura de Luis María Martínez, Siervo de Dios, en la Web 2.0. YouTube", Intersticios Sociales, Guadalajara, año 5, núm. 10, sep. 2015. También en: <http://www.intersticiossociales. com/ediciones/numero_10.html>, o <http://www.redalyc.org/articulo. oa? id=421741049001>.

. "Santo conspirador u hombre de paz y caridad? El fabuloso destino de Luis María Gonzaga Martínez, Siervo de Dios”, en Elizabeth Judd y Fortunato Mallimaci, Cristianismos en América Latina, Buenos Aires, Clacso-Crop, 2013 (Tiempo Presente, Historias y Memorias), pp. 29-59. Spadaro, Antonio, Cybertheology. Thinking Christianity in the Era of the Internet, tr. María Way, Nueva York, Fordham University Press, 2014.

Stadick, Anna. "Saint Patrons: The Role of Archives in The Roman Catholic Process Of Canonization”, Archival Issues, vol. 24, núm. 2, 1999, pp. 123-143.

Taylor, Anna. "Hagiography and Early Medieval History", Religion Compass, vol. 7, núm. 1, January 2013, pp. 1-14. Academic Search Complete, EBscohost.

Veraja, Fabijan. La beatificazione. Storia. Problemi. Prospettive, Roma, S. Congregazione per i cause dei santi, 1983 (Sussidi per le studio delle cause dei santi, 2).

Wagner, Rachel. Godwired Religion. Ritual and Virtual Reality, Londres, Routledge, 2012.

William, F. Jasper. "Cristeros' Rallying Cry for Christ”, New American, vol. 28, núm. 17, September 3, 2012, pp. 32-39. Academic Search Complete, EBscohost.

Williams, S. Taylor. "Illness Narrative. Depression, and Sainthood: An Analysis of the Writings of Mother Teresa”, Journal Of Religion \& Heal- 
th, vol. 53, núm. 1, February 2014, pp. 290-297. Academic Search Complete, EBscohost.

Woodward, Kenneth L. Making Saints. How the Catholic Church Determines Who Became a Saint, Who Doesn't, and Why, Nueva York, Simon and Schuster, 1990. 